\title{
Leveraging big data to guide better nurse staffing strategies
}

\author{
Joanne Spetz
}

\section{Correspondence to}

Professor Joanne Spetz, Philip R. Lee Insitute for Health Policy Studies, University of California, San Francisco, CA 94118, USA; joanne.spetz@ucsf.edu

Accepted 6 July 2020 Published Online First 27 July 2020

\section{Sinked}

- http://dx.doi.org/10.1136/ bmjqs-2019-010569

\section{Check for updates}

(c) Author(s) (or their employer(s)) 2021. No commercial re-use. See rights and permissions. Published by BMJ.

To cite: Spetz J. BMJ Qual Saf 2021;30:1-3.
Over the past 20 years, a large body of research has documented a relationship between higher nurse-to-patient staffing ratios and better patient outcomes, including shorter hospital stays, lower rates of failure to prevent mortality after an in-hospital complication, inpatient mortality for multiple types of patients, hospital-acquired pneumonia, unplanned extubation, respiratory failure and cardiac arrest. ${ }^{1-5}$ In addition, patients report higher satisfaction when they are cared for in hospitals with higher staffing levels. ${ }^{67}$

To date, most studies have not identified an 'optimal' nurse staffing ratio, ${ }^{8}$ which creates a challenge for determining appropriate staffing levels. If increasing nurse staffing always produces at least some improvement in the quality of care, how does one determine what staffing level is best? This decision is ultimately an economic one, balancing the benefits of nurse staffing with the other options for which those resources could be used. It is in this context that hospitals develop staffing plans, generally based on historical patterns of patient acuity.

\section{PRACTICAL CHALLENGES OF NURSE STAFFING}

Hospital staffing plans provide the structure necessary for determining hiring and scheduling, but fall short for a number of reasons. First, there are multiple ways in which patient acuity can be measured, which can have measurable effects on the staffing levels resulting from acuity models. ${ }^{9}$ Second, patient volume and acuity can shift rapidly with changes in the volume of admissions, discharges and transfers between units. Third, staffing plans provide little guidance regarding the optimal mix of permanent staff, variable staff and externally contracted staff.

The paper by Saville and colleagues ${ }^{10}$ in this issue of BMJ Quality \& Safety addresses the latter two issues by applying a simulation model to identify the optimal target for baseline nurse staffing in order to minimise periods of understaffing. Included in this model is consideration of the extent to which hospitals should leverage temporary personnel (typically obtained through an external agency) to fill gaps. The model acknowledges the likelihood that a hospital cannot realistically prevent all shifts from having a shortfall of nurses at all times, as well as the reality that hospital managers lack information about the best balance between permanent and temporary staff. In addition, the analysis includes a calculation of the costs of each staffing approach, drawing from the records of 81 inpatient wards in four hospital organisations.

The application of sophisticated simulation models and other advanced analyticl approaches to analysis of nurse staffing has been limited to date, and this paper is an exemplar of the value of such research. Recent studies have used machine learning methods to forecast hospital discharge volume, ${ }^{11}$ a discrete event simulation model to determine nursing staff needs in a neonatal intensive care unit, ${ }^{12}$ and a prediction model using machine learning and hierarchical linear regression to link variation in nurse staffing with patient outcomes. ${ }^{13}$ This new study applied a unique Monte Carlo simulation model to estimate demand for nursing care and test different strategies to meet demand.

The results of the analysis are not surprising in that hospitals are much less likely to experience understaffed patient shifts if they aim to have higher baseline staffing. The data demonstrate a notable leftward skew, indicating that hospitals are more likely to have large unanticipated increases in patient volume and acuity than to have unanticipated decreases. This results in hospitals being more likely to have shifts that are understaffed than 
shifts that are overstaffed, which inevitably places pressure on hospitals to staff at a higher level and/or have access to a larger pool of temporary nurses. It also is not surprising that hospitals will need to spend more money per patient day if they aim to reduce the percent of shifts that are understaffed. What is surprising about the results is that hospitals do not necessarily achieve cost savings by relying on temporary personnel versus setting regular staffing at a higher level.

\section{TRADE-OFFS BETWEEN PERMANENT AND TEMPORARY STAFF}

The temporary nursing workforce enables healthcare facilities to maintain flexible yet full care teams based on patient care needs. Hospitals can use temporary nurses to address staffing gaps during leaves of absence, turnover or gaps between recruitment of permanent nurses, as well as during high-census periods. Temporary personnel are typically more expensive on an hourly basis than permanent staff. In addition, overreliance on temporary staff can have detrimental effects on permanent nurses' morale and motivation. Orientations prior to shifts are often limited, which leads to a twofold concern as temporary nurses feel illprepared for shifts and permanent staff feel flustered when required to bring the temporary nurse up to speed while being expected to continue normal operations. ${ }^{14}$ Agency nurses may be assigned to patients and units that are incongruent with their experience and skills-either to unfamiliar units, which affects their ability to confidently deliver care, or to less complex patients where they feel as if their skills are not used adequately. ${ }^{1415}$ These issues can create tension between temporary and permanent nursing staff, which can be compounded by the wage disparity. Permanent staff might feel demoralised and expendable when working alongside temporary staff who are not integrated into the social fabric of the staff. ${ }^{16}$

Hospital managers also must be cognisant of the potential quality impact of relying heavily on temporary nursing staff. Research on the impact of contingent nursing employment on costs and quality have often found negative effects on quality, including mortality, and higher costs. ${ }^{1718}$ However, other studies have found that the association between temporary nursing staff and low quality result from general shortages of nursing staff, which make a hospital more likely to employ temporary staff, and not directly from the contingent staff. ${ }^{19-21}$ Thus, temporary nurses play an important role in alleviating staffing shortages that would otherwise lead to lower quality of care. ${ }^{22}$

\section{CHARTING A PATH FORWARD IN HOSPITAL MANAGEMENT AND HEALTHCARE RESEARCH}

The maturation of electronic health records and expansion of computerised healthcare management systems provide opportunities both for improved decision making about workforce deployment and for advanced workforce research. In the area of workforce management, nursing and other leaders have a growing array of workforce planning tools available to them. Such tools are most effective when they display clear information about predicted patient needs and staff availability, but managers still must rely on their on-the-ground understanding of their staff and their context of patient care. ${ }^{23}$ Integration of human resources data with patient outcomes data has revealed that individual nurses and their characteristics have important discrete effects on the quality of care. ${ }^{24}$ Future development of workforce planning tools should translate this evidence to practice. In addition, new technology platforms are emerging to facilitate direct matching between temporary healthcare personnel and healthcare organisations. One recent study tested a smartphone-based application that allowed for direct matching of locum tenens physicians with a hospital in the English National Health Service, finding that the platform generated benefits including greater transparency and lower cost. $^{26}$ Similar technologies for registered nurses could facilitate better matching between hospital needs and temporary nurses' preparedness to meet those needs.

Analytical methods that fully leverage the large datasets compiled through electronic health records, human resources systems and other sources can be applied to advance research on the composition of nursing teams to improve quality of care. As noted above, prior research has applied machine learning and discrete event simulation to analyses of healthcare staffing. Other recent studies have leveraged natural language processing of nursing notes to identify fall risk factors ${ }^{27}$ and applied data mining of human resources records to understand the job titles held by nurses. ${ }^{28}$ Linking these rapidly advancing analytical approaches that assess the outcomes and costs of nurse staffing strategies, such as the work by Saville and colleagues published in this issue, to data on the impact of nurse staffing on the long-term costs of patient care will further advance the capacity of hospital leaders to design cost-effective policies for workforce deployment.

Funding The authors have not declared a specific grant for this research from any funding agency in the public, commercial or not-for-profit sectors.

Competing interests None declared.

Patient consent for publication Not required.

Provenance and peer review Commissioned; internally peer reviewed.

\section{REFERENCES}

1 Kane RL, Shamliyan TA, Mueller C, et al. The association of registered nurse staffing levels and patient outcomes: systematic review and meta-analysis. Med Care 2007;45:1195-204. 
2 Needleman J, Buerhaus P, Pankratz VS, et al. Nurse staffing and inpatient hospital mortality. N Engl J Med 2011;364:1037-45.

3 Lee SE, Scott LD. Hospital nurses' work environment characteristics and patient safety outcomes: a literature review. West J Nurs Res 2018;40:121-45.

4 Ball JE, Bruyneel L, Aiken LH, et al. Post-Operative mortality, missed care and nurse staffing in nine countries: a crosssectional study. Int J Nurs Stud 2018;78:10-15.

5 Griffiths P, Maruotti A, Recio Saucedo A, et al. Nurse staffing, nursing assistants and hospital mortality: retrospective longitudinal cohort study. BMJ Qual Saf 2019;28:609-17.

6 Oppel E-M, Young GJ. Nurse staffing patterns and patient experience of care: an empirical analysis of U.S. hospitals. Health Serv Res 2018;53:1799-818.

7 Aiken LH, Sloane DM, Ball J, et al. Patient satisfaction with hospital care and nurses in England: an observational study. BMJ Open 2018;8:e019189.

8 Needleman J, Shekelle PG. More ward nursing staff improves inpatient outcomes, but how much is enough? BMJ Qual Saf 2019;28:603-5.

9 Mark BA, Harless DW. Adjusting for patient acuity in measurement of nurse staffing: two approaches. Nurs Res 2011;60:107-14.

10 Saville C, Monks T, Griffiths P, et al. Costs and consequences of using average demand to plan baseline nurse staffing levels: a computer simulation study. BMJ Qual Saf 2021;30:7-16.

11 McCoy TH, Pellegrini AM, Perlis RH. Assessment of timeseries machine learning methods for forecasting hospital discharge volume. JAMA Netw Open 2018;1:e184087.

12 DeRienzo CM, Shaw RJ, Meanor P, et al. A discrete event simulation tool to support and predict hospital and clinic staffing. Health Informatics J 2017;23:124-33.

13 Tawfik DS, Profit J, Lake ET, et al. Development and use of an adjusted nurse staffing metric in the neonatal intensive care unit. Health Serv Res 2020;55:190-200.

14 Birmingham C, van de Mortel T, Needham J, et al. The experiences of the agency registered nurse: an integrative literature review. J Nurs Manag 2019;27:1580-7.

15 Simpson K, Simpson R. What do we know about our agency nurse population? A scoping review. Nurs Forum 2019;54:492-8.
16 Lapalme Marie-Ève, Guerrero S. How do I stand compared to agency workers? justice perceptions and employees' counterproductive work behaviours. J Nurs Manag 2019;27:1471-8.

17 Dall'Ora C, Maruotti A, Griffiths P. Temporary staffing and patient death in acute care hospitals: a retrospective longitudinal study. J Nurs Scholarsh 2020;52:210-6.

18 Estabrooks CA, Midodzi WK, Cummings GG, et al. The impact of hospital nursing characteristics on 30-day mortality. Nurs Res 2005;54:74-84.

19 Aiken LH, Xue Y, Clarke SP, et al. Supplemental nurse staffing in hospitals and quality of care. J Nurs Adm 2007;37:335-42.

20 Xue Y, Aiken LH, Freund DA, et al. Quality outcomes of hospital supplemental nurse staffing. J Nurs Adm 2012;42:580-5.

21 Lasater KB, Sloane DM, Aiken LH. Hospital employment of supplemental registered nurses and patients' satisfaction with care. J Nurs Adm 2015;45:145-51.

22 Aiken LH, Shang J, Xue Y, et al. Hospital use of agencyemployed supplemental nurses and patient mortality and failure to rescue. Health Serv Res 2013;48:931-48.

23 Burton CR, Rycroft-Malone J, Williams L, et al. NHS managers' use of nursing workforce planning and deployment technologies: a realist synthesis. Southampton (UK), 2018.

24 Yakusheva O, Lindrooth R, Weiss M. Nurse value-added and patient outcomes in acute care. Health Serv Res 2014;49:1767-86.

25 Yakusheva O, Weiss M. Rankings matter: nurse graduates from higher-ranked institutions have higher productivity. $B M C$ Health Serv Res 2017;17:134.

26 Theodoulou I, Reddy AM, Wong J. Is innovative workforce planning software the solution to NHS staffing and cost crisis? an exploration of the locum industry. BMC Health Serv Res 2018;18:188.

27 Bjarnadottir RI, Lucero RJ. What can we learn about fall risk factors from EHR nursing notes? A text mining study. EGEMS 2018;6:21.

28 Leary A, Maclaine K, Trevatt P, et al. Variation in job titles within the nursing workforce. J Clin Nurs 2017;26:4945-50. 